\title{
Calidad bromatológica del pasto kikuyo en respuesta a la inoculación con hongos micorrícicos y fertilización química
}

\author{
Bromatological quality of kikuyu grass in response to inoculation with \\ mycorrhizal fungi and chemical fertilization
}

\author{
Alejandro Ortiz A. ${ }^{1}$, Elkin Arboleda Z. ${ }^{2}$, Marisol Medina S. ${ }^{1,3}$
}

\section{Resumen}

El kikuyo (Cenchrus clandestinus) es la gramínea predominante en el trópico alto colombiano y es el principal forraje en sistemas de lechería especializada; sin embargo, debe ser sometido a altas dosis de nitrógeno $(\mathrm{N})$ y fósforo $(\mathrm{P})$ de fuentes químicas. El objetivo del trabajo fue evaluar el efecto de los hongos formadores de micorrizas arbusculares - HFMA (Rhizophagus intraradices y Rhizophagus manihotis) bajo tres niveles de fertilización con $\mathrm{N}\left(0[0 \%], 200\right.$ [50\%] y $400 \mathrm{~kg} \mathrm{~N} \mathrm{ha}^{-1}$ año $\left.{ }^{-1}[100 \%]\right)$ y P $(0$ [0\%], 100 [50\%] y $\left.200 \mathrm{~kg} \mathrm{P} \mathrm{ha}^{-1} \mathrm{año}^{-1}[100 \%]\right)$ en el contenido de materia seca (MS\%), proteína cruda (PC\%), energía bruta (EB), calcio $(\mathrm{Ca} \%)$ y $\mathrm{P}(\mathrm{P} \%)$ en el kikuyo. Este estudio se realizó con las plantas sembradas en potes y bajo condiciones de casa malla. Los resultados indican que el uso de HFMA en el programa de fertilización mejoró algunas variables bromatológicas del pasto kikuyo, similar a lo encontrado con la aplicación de $400 \mathrm{~kg}$ $\mathrm{N}$ ha ${ }^{-1}$ año ${ }^{-1}$ y $100 \mathrm{~kg} \mathrm{P} \mathrm{ha}^{-1}$ año ${ }^{-1}$ que tuvieron efecto positivo en la concentración de proteína y energía del pasto. Los HFMA no afectaron $(\mathrm{p}>0.05)$ la calidad del forraje; sin embargo $R$. intraradices mostró ser más eficiente en la toma de $\mathrm{N}$ y el $\mathrm{P}$ del suelo.

Palabras clave: calcio, colonización micorrizal, energía bruta, fósforo, proteína cruda

\footnotetext{
${ }^{1}$ Grupo de Investigación en Ciencias Agrarias (GRICA), Escuela de Producción Agropecuaria, Facultad de Ciencias Agrarias, Universidad de Antioquia, Medellín, Colombia

${ }^{2}$ Grupo de Investigación en Agrociencias, Biodiversidad y Territorio (GaMMA), Escuela de Producción Agropecuaria, Facultad de Ciencias Agrarias, Universidad de Antioquia, Medellín, Colombia

${ }^{3}$ E-mail: marisol.medina@udea.edu.co; https://orcid.org/0000-0003-1929-8305
}

Recibido: 18 de marzo de 2020

Aceptado para publicación: 18 de diciembre de 2020

Publicado: 23 de junio de 2021

(CLos autores. Este artículo es publicado por la Rev Inv Vet Perú de la Facultad de Medicina Veterinaria, Universidad Nacional Mayor de San Marcos. Este es un artículo de acceso abierto, distribuido bajo los términos de la licencia Creative Commons Atribución 4.0 Internacional (CC BY 4.0) [https:// creativecommons.org/licenses/by/4.0/deed.es] que permite el uso, distribución y reproducción en cualquier medio, siempre que la obra original sea debidamente citada de su fuente original 


\begin{abstract}
Kikuyu (Cenchrus clandestinus) is the predominant grass in the Colombian high tropics and is the main forage in specialized dairy systems; however, it must be subjected to high doses of nitrogen $(\mathrm{N})$ and phosphorus $(\mathrm{P})$ from chemical sources. The aim of this study was to evaluate the effect of the arbuscular mycorrhizal fungi - FMA (Rhizophagus intraradices and Rhizophagus manihotis) under three levels of fertilization with $\mathrm{N}(0$ $[0 \%], 200[50 \%]$ and $400 \mathrm{~kg} \mathrm{~N} \mathrm{ha}^{-1}$ year $\left.^{-1}[100 \%]\right)$ and $\mathrm{P}(0[0 \%], 100[50 \%]$ and $200 \mathrm{~kg} \mathrm{P} \mathrm{ha-}$ ${ }^{1}$ year $\left.^{-1}[100 \%]\right)$ in dry matter content (DM\%), crude protein (PC\%), gross energy (EB), calcium $(\mathrm{Ca} \%)$ and $\mathrm{P}(\mathrm{P} \%)$ in kikuyo. This study was carried out with the plants sown in pots and under mesh house conditions. The results indicate that the use of HFMA in the fertilization program improved some bromatological variables of the kikuyo grass, like what was found with the application of $400 \mathrm{~kg} \mathrm{~N} \mathrm{ha}^{-1}$ year $^{-1}$ and $100 \mathrm{~kg} \mathrm{P} \mathrm{ha}^{-1}$ year $^{-1}$ which had positive effect on the protein concentration and grass energy. The FMA did not affect ( $\mathrm{p}>0.05$ ) the quality of the forage; however, $R$. intraradices showed to be more efficient in the uptake of $\mathrm{N}$ and $\mathrm{P}$ from the soil.
\end{abstract}

Key words: calcium, mycorrhizal colonization, gross energy, phosphorus, crude protein

\section{INTRODUCCIÓN}

El uso de fertilizantes químicos para mejorar la fertilidad de los suelos, la productividad y la calidad de los cultivos puede afectar negativamente el complejo sistema de los ciclos biogeoquímicos (Steinshamn et al., 2004), causando la lixiviación y escorrentía de nutrientes, especialmente nitrógeno $(\mathrm{N}) \mathrm{y}$ fósforo $(\mathrm{P})$, contaminando el medio ambiente (Gyaneshwar et al., 2002). Los excesos de nutrientes, además de los daños ambientales, afectan negativamente el crecimiento y la calidad composicional de las plantas.

De otra parte, el número de publicaciones científicas sobre el uso eficiente de microorganismos del suelo que mejoren la toma y disponibilidad de nutrientes ha ido en amento (Adesemoye y Klopper, 2009). Dentro de esos microorganismos se encuentran los hongos formadores de micorrizas arbusculares (HFMA), dada la capacidad de influir en el crecimiento de las plantas, la toma de agua y el contenido de nutrientes de estas (Giovannetti et al., 2006), considerando que las hifas de los HFMA pueden tomar $\mathrm{N}$ y $\mathrm{P}$ y llevarlo hasta la planta (Aseri et al., 2008). Con el fin de evitar efectos cruzados entre micorrizas, los tratamientos se desarrollaron bajo condiciones controladas con plantas sembradas en potes y bajo condiciones de casa malla, la cual es una estructura de protección construida a base de mallas plásticas, cables y tubulares de hierro galvanizado con el fin de aislar y controlar el desarrollo de las plantas (Alvarado et al., 2014).

En Colombia, el pasto kikuyo (Cenchrus clandestinus [Hochst. ex Chiov] Morrone), es una planta de gran importancia en sistemas pecuarios de producción de leche en trópico alto (Correa et al., 2011), principalmente por su crecimiento agresivo (Estrada, 2001), aunque requiere altos niveles de fertilización química para incrementar la producción de forraje verde y producir forrajes de calidad para la alimentación de vacas lecheras. La fertilización con $\mathrm{N}$ recomendada está entre 50 y $70 \mathrm{~kg}$ de nitrógeno por hectárea por pastoreo, correspondiente al menos a una dosis de $400 \mathrm{~kg} \mathrm{~N} \mathrm{ha}^{-1} \mathrm{año}^{-1}$, lo cual incrementa los costos de producción y la contaminación ambiental (Echeverri et al., 2010). 
Debido a esto, el objetivo de esta investigación fue determinar la calidad composicional del pasto kikuyo mediante evaluación de algunas variables bromatológicas al aplicar diferentes dosis de fertilizantes nitrogenados y fosfóricos en asociación con algunos HFMA y el efecto de estos últimos en la absorción de nutrientes como el $\mathrm{P}$ disponible en el suelo.

\section{Materiales y Métodos}

\section{Sitio de Estudio}

El experimento se desarrolló bajo condiciones de casa malla (Alvarado et al., 2014) en el corregimiento de San Cristóbal, municipio de Medellín, Colombia, a una altitud de $1860 \mathrm{msnm}$, temperatura promedio de $21^{\circ} \mathrm{C}$, precipitación promedia anual de $1575 \mathrm{~mm}$. Para el estudio, se establecieron potes con suelo esterilizado e inoculado con 94 esporas en promedio por gramo de los HFMA identificadas en estudios previos (Ortiz et al., 2017).

\section{Siembra de Pasto Kikuyo}

La semilla sexual del pasto maduro se obtuvo de los lotes de las fincas de donde se seleccionaron previamente los HFMA nativos (Ortiz et al., 2017). La siembra se realizó en potes plásticos de $16 \times 8 \mathrm{~cm}$ de diámetro y área de $50.26 \mathrm{~cm}^{2}$, con suelo esterilizado en autoclave a $120{ }^{\circ} \mathrm{C}$ durante $20 \mathrm{minu}$ tos. Se utilizaron cinco semillas sexuales de pasto; asimismo, el inóculo de HFMA para cada cepa correspondió a $4 \mathrm{~g}$ de inoculante con un contenido de 94 esporas promedio por gramo. Los fertilizantes se aplicaron de acuerdo con los tratamientos propuestos.

\section{Fertilización Nitrogenada, Fosfórica y HFMA}

Para la fertilización nitrogenada de $100 \%$ se empleó la máxima dosis reportada (Dianelis et al., 1994) de $400 \mathrm{~kg} \mathrm{~N} \mathrm{ha}^{-1}$ año $^{-1}$ o $50 \mathrm{~kg} \mathrm{~N} \mathrm{ha}^{-1}$ corte $^{-1}$ en pasto kikuyo, usan- do como fuente urea grado (46-0-0). Además, el $100 \%$ de la dosis del fertilizante fosfórico fue de $200 \mathrm{~kg} \mathrm{P} \mathrm{ha}{ }^{-1}$ año $^{-1}$ o $25 \mathrm{~kg} \mathrm{P}$ ha $^{-1}$ corte $^{-1}$ (Diannelis et al., 1994), usando como fuente roca fosfórica $\left(31.59 \mathrm{P}_{2} \mathrm{O}_{5} \mathrm{y}\right.$ $39.34 \mathrm{CaO}$ ). Los fertilizantes se aplicaron 10 días posteriores a la siembra y después de cada corte. La cantidad de fertilizante por pote se calculó a partir del área de este $(50.26$ $\mathrm{cm}^{2}$ o $0.5026 \mathrm{~m}^{2}$ ). Las dosis por pote aplicadas fueron $2.51 \mathrm{~g} \mathrm{~N}_{\text {pote }}$ corte $^{-1}$ y $1.26 \mathrm{~g} \mathrm{P}$ pote $^{-1}$ corte $^{-1}$.

Los HFMA empleados se denominaron nativo 1 (Rhizophagus intraradices), nativo 2 (Rhizophagus fasciculatus) y una cepa conocida (Rhizophagus manihotis). El análisis químico del suelo indicó condición alta de acidez y bajo contenido de calcio y fósforo intercambiables (Cuadro 1). Se aplicaron $2000 \mathrm{~kg} / \mathrm{ha}$ de cal dolomita 30 días antes de la siembra.

\section{Variables de Calidad}

Para evaluar la calidad nutricional del pasto se determinaron las variables materia seca según AOAC (1990), la proteína cruda por el método de Kjeldahl (AOAC, 1995), la energía bruta a través del método de la bomba calorimétrica, el contenido de calcio (Ca) por el método de complexométrica con EDTA y el $\mathrm{P}$ con el método de espectometría UV-VIS, NTC 4981 (Ayala, 2007). Para la interpretación del contenido energético del pasto, esta se convirtió de energía bruta $(\mathrm{EB})$ a energía digestible (ED) y luego a energía metabolizable (EM), donde la ED es el $60 \%$ de la EB y la EM el $82 \%$ de la ED (Agudelo, 2001). Los cortes se realizaron en tres ciclos de 35 días cada uno para una duración total del estudio de 105 días. En cada periodo de corte se midieron las variables de calidad y después del último ciclo se determinaron las isotermas de fósforo y el porcentaje de colonización de raíces. El ciclo de 35 días para cada cosecha se determinó a partir de formación de la cuarta y quinta hoja bien desarrollada (Chopra et al., 2007). El pasto se cosechó a una altura de $10 \mathrm{~cm}$ (Swanepoel et al., 2013). 


\section{Isotermas de Fósforo}

Las isotermas de absorción de $\mathrm{P}$ se realizaron mediante la metodología descrita por Fox y Kamprath (1970) y Habte y Osorio (2001). Las tres concentraciones de P en la solución del suelo expresada en $\mathrm{KH}_{2} \mathrm{PO}_{4}$ $\mathrm{kg}^{-1}$ de suelo fueron 2, 3.8 y $17.6 \mathrm{KH}_{2} \mathrm{PO}_{4}$ $\mathrm{kg}^{-1}$ de suelo (Fox y Kamprath, 1970; Sierra et al. 2012).

\section{Tinción de Raíces y Porcentaje de Colo- nización}

El método utilizado fue el propuesto por Phillips y Hayman (1970) y Sieverding (1984), el cual requiere el montaje de raíces teñidas en portaobjetos para evaluarse en microscopio óptico. El porcentaje de colonización se determinó a partir de la siguiente fórmula: Colonización $(\%)=($ Número de intersectos micorrizados / Número de intersectos observados) * 100. El número mínimo de intersecciones observadas fue de 100 (Giovannetti y Mosse, 1980).

\section{Diseño Experimental}

Se empleó un diseño de clasificación experimental completamente aleatorizado mediante arreglo factorial $(3 \times 3 \times 3)$ asimétrico de tipo balanceado, efecto fijo, de medidas repetidas en el tiempo. Se evaluaron las variables de calidad del pasto, colonización de las raíces y la capacidad de absorción de fósforo del suelo. Se incorporó el análisis multivariante de la varianza (MANOVA) con contraste canónico ortogonal determinando vía máxima verosimilitud para la comparación del efecto de los tratamientos, suplementado con análisis de tipo unidimensional que tiene como objetivo establecer los estadísticos media aritmética, desviación típica y coeficiente de variación.

El modelo de clasificación experimental fue Yijsk $=u+P i+N j+H F M A s+$ PNij + PHFMAis + NHFMAjS + PNHFMAijs $+e K(i j s)$, donde Yijsk = Va- riable de respuesta calidad composicional, porcentaje de colonización en las raíces en el pasto kikuyo y capacidad de absorción de fósforo del suelo en la l-ésima observación correspondiente al efecto i-ésimo nivel del fósforo, j-ésimo nivel de nitrógeno y k-ésimo categoría de hongos formadores de micorrizas; $U$ : Media poblacional; $P i$ : i-ésima observación del efecto del fósforo $\mathrm{Nj}$ : i-ésima observación del efecto del nitrógeno; HFMAs: i-ésima observación del efecto de los hongos formadores de micorrizas PNij: iésima observación del efecto combinado del fósforo y el nitrógeno; PHFMAis: i-ésima observación del efecto combinado del fósforo con los hongos formadores de micorrizas, NHFMAjs: i-ésima observación del efecto combinado del nitrógeno con los hongos formadores de micorrizas, PNHFMAijs: iésima observación del efecto combinado del fósforo y el nitrógeno con los hongos formadores de micorrizas, $E k(i j s)$ : Error experimental.

Los factores experimentales fueron Factor 1. Fertilización fosfórica (P) con tres niveles $(0,50,100 \%) ;$ Factor 2 . Fertilización nitrogenada $(\mathrm{N})$ con tres niveles $(0,5 \%$, $100 \%)$, Factor 3. Hongos micorrícicos (HFMA) con tres niveles (sin micorrizas, Rhizophagus intraradices, Rhizophagus manihotis). Se implementaron 27 tratamientos con tres repeticiones por tratamiento para un total de 81 unidades experimentales.

\section{Resultados y Discusión}

\section{Calidad del Forraje}

\section{Materia seca}

El tratamiento de $\mathrm{N}$ como efecto simple afectó negativamente el rendimiento de MS ( $<<0.05)$, mientras que los tratamientos con $P$ y HFMA no tuvieron efecto significativo, tanto como efectos simples como la interacción de todas las variables independientes (Figura 1). Apráez y Moncayo (2003), 
Cuadro 1. Propiedades fisicoquímicas básicas del suelo usado para el ensayo

\begin{tabular}{|c|c|c|c|c|c|}
\hline Parámetro & Unidad & Valor & Parámetro & Unidad & Valor \\
\hline Arena & $\mathrm{g} \mathrm{kg}^{-1}$ & 68 & $\mathrm{P}$ & $\mathrm{mg} \mathrm{kg}^{-1}$ & 5 \\
\hline Limo & $\mathrm{g} \mathrm{kg}^{-1}$ & 10 & $\mathrm{~S}$ & $\mathrm{mg} \mathrm{kg}^{-1}$ & 3 \\
\hline Arcilla & $\mathrm{g} \mathrm{kg}^{-1}$ & 22 & $\mathrm{Fe}$ & $\mathrm{mg} \mathrm{kg}^{-1}$ & 576 \\
\hline Clase & & FArA & $\mathrm{Mn}$ & $m g \mathrm{~kg}^{-1}$ & 5 \\
\hline $\mathrm{pH}$ & & 4.5 & $\mathrm{Cu}$ & $m g \mathrm{~kg}^{-1}$ & 1 \\
\hline $\begin{array}{l}\text { Materia } \\
\text { Orgánica }\end{array}$ & $\mathrm{g} \mathrm{kg}^{-1}$ & 14 & $\mathrm{Zn}$ & $\mathrm{mg} \mathrm{kg}^{-1}$ & 3 \\
\hline $\mathrm{Al}$ & Cmolc kg-1 & 1.6 & B & $\mathrm{mg} \mathrm{kg}^{-1}$ & 0,61 \\
\hline $\mathrm{Ca}$ & Cmolc kg-1 & 0.57 & $\mathrm{~N}-\mathrm{NO}_{3}$ & $\mathrm{mg} \mathrm{kg}^{-1}$ & 55 \\
\hline $\mathrm{Mg}$ & Cmolc kg-1 & 0.25 & $\mathrm{~N}-\mathrm{NO}_{4}$ & $\mathrm{mg} \mathrm{kg}^{-1}$ & 43 \\
\hline K & Cmolc kg-1 & 0.22 & & & \\
\hline
\end{tabular}

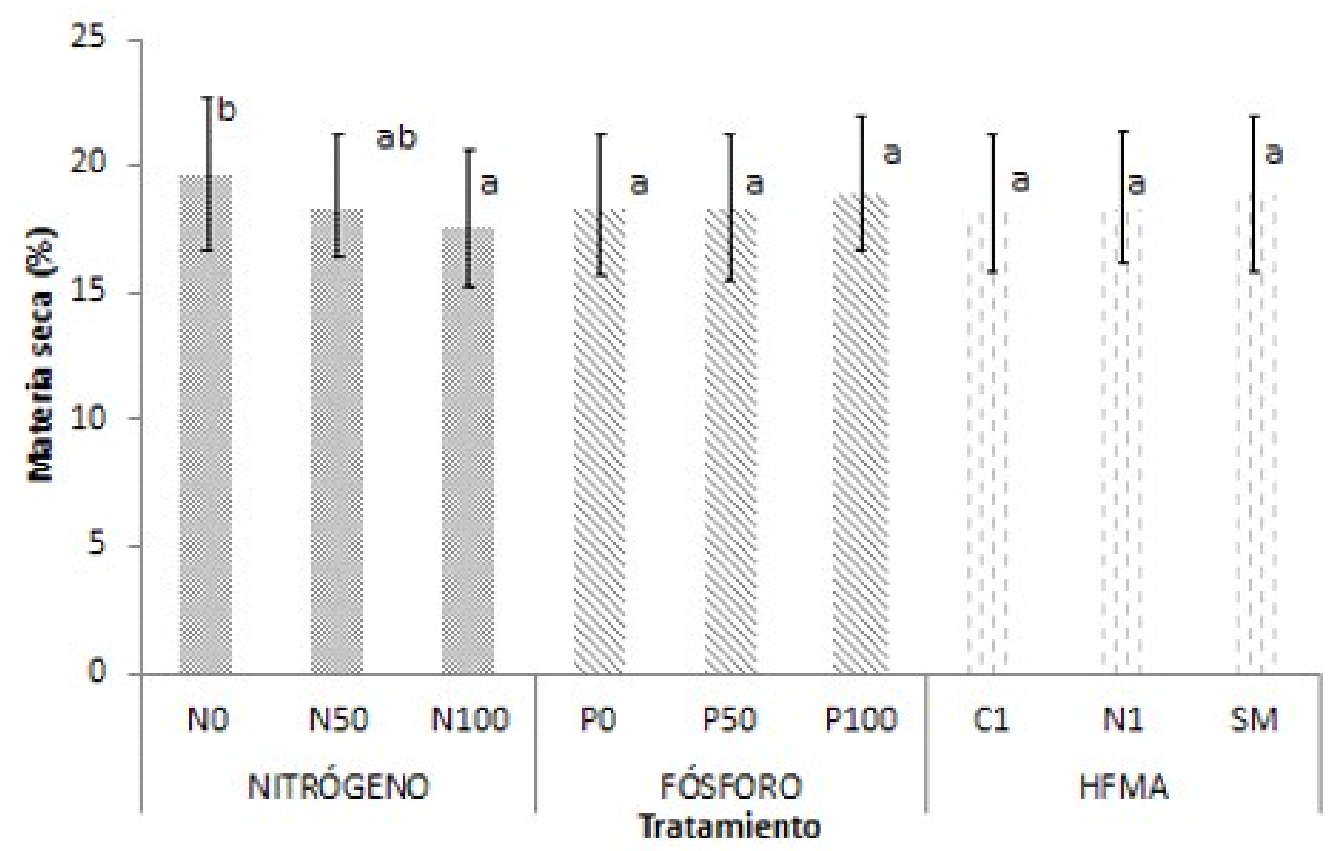

Figura 1. Efecto de la fertilización del suelo y de hongos formadores de micorrizas arbusculares (HFMA) sobre el porcentaje de materia seca del pasto kikuyo (Cenchrus clandestinus). Letras diferentes dentro de cada grupo de tratamiento indican diferencias $(\mathrm{p}<0.05)$. Tratamientos: Nitrógeno $(0,50$ y $100 \%)$, Fósforo $(0,50$ y $100 \%)$ y HFMA (C1: Cepa conocida Rhizophagus manihotis, N1: Nativo 1 Rhizophagus intraradices, SM: sin micorrizas) 


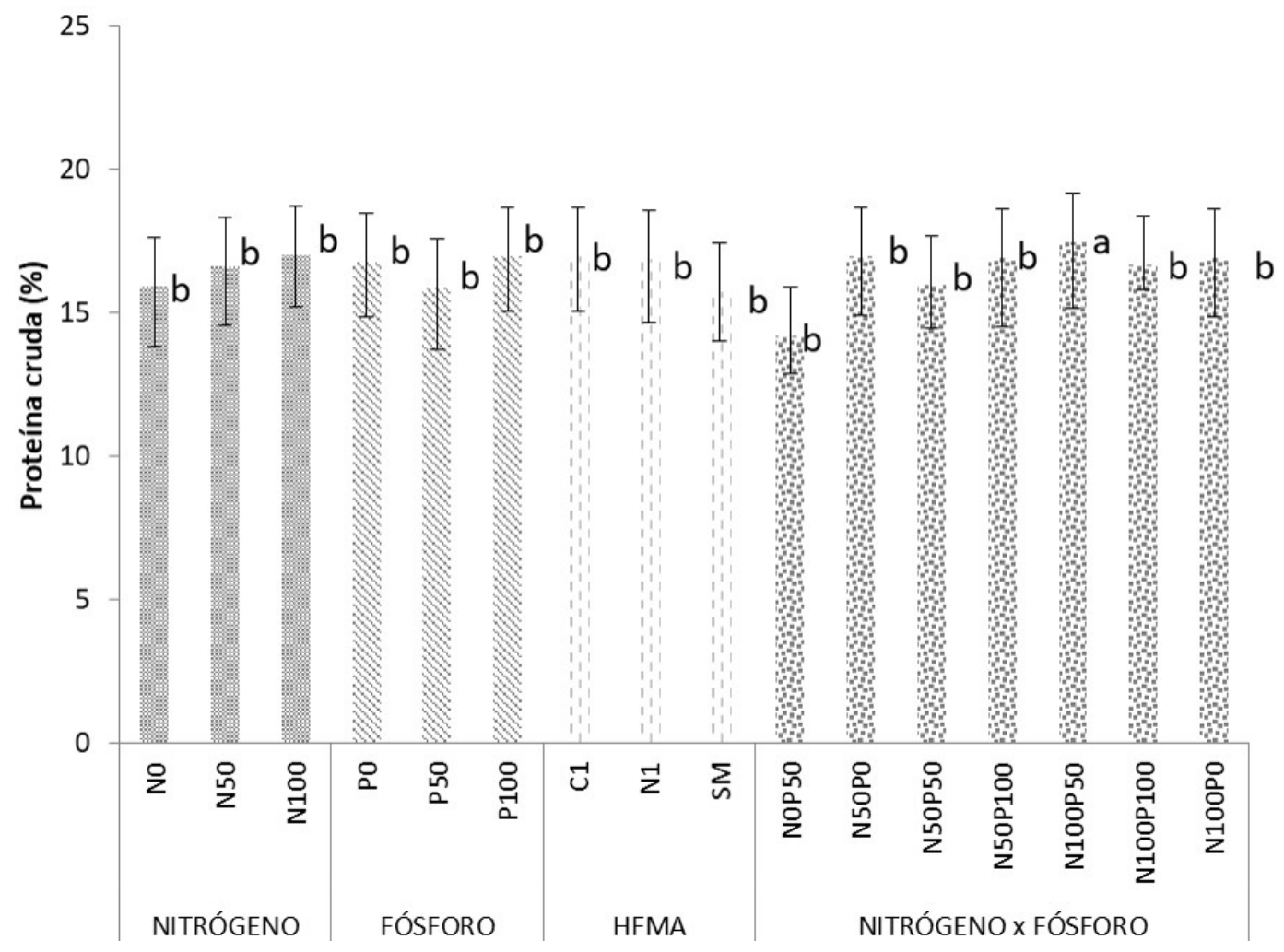

Figura 2. Efecto de la fertilización del suelo y de hongos formadores de micorrizas arbusculares (HFMA) sobre el porcentaje de proteína cruda del pasto kikuyo (Cenchrus clandestinus). Letras diferentes dentro de cada grupo de tratamiento indican diferencias $(\mathrm{p}<0.05)$. Tratamientos: Nitrógeno $(0,50$ y $100 \%)$, Fósforo $(0,50$ y $100 \%)$ y HFMA (C1: Cepa conocida Rhizophagus manihotis, N1: Nativo 1 Rhizophagus intraradices, SM: sin micorrizas)

en forma similar, encontraron un menor porcentaje de MS cuando se aplicaron fertilizantes químicos. Los cambios en el contenido de MS en las pasturas pueden estar relacionados con una menor humedad retenida en los tejidos vegetales (Apráez y Moncayo, 2003) $\mathrm{y}$ al papel que juega el $\mathrm{N}$ en la toma de agua por parte de la planta, ya que a medida que aumenta la aplicación de $\mathrm{N}$ se aumenta el crecimiento de la planta y, por tanto, el consumo de agua desde el suelo (Teixeira et al., 2014).

\section{Proteína cruda}

El contenido de PC fue significativamente diferente en la interacción $\mathrm{N}-\mathrm{P}$, habiendo un mayor efecto entre los niveles N100-P50 (17.44\% PC) (p<0.05; Figura 2). La máxima dosis de N100 (400 kg N ha año$\left.{ }^{1}\right)$ en combinación con una dosis media de P50 (100 kg P ha año-1) mostró la mayor concentración de PC (Figura 2). Esto indica que la aplicación de ambos elementos mejora considerablemente la nutrición de la planta. Al- 


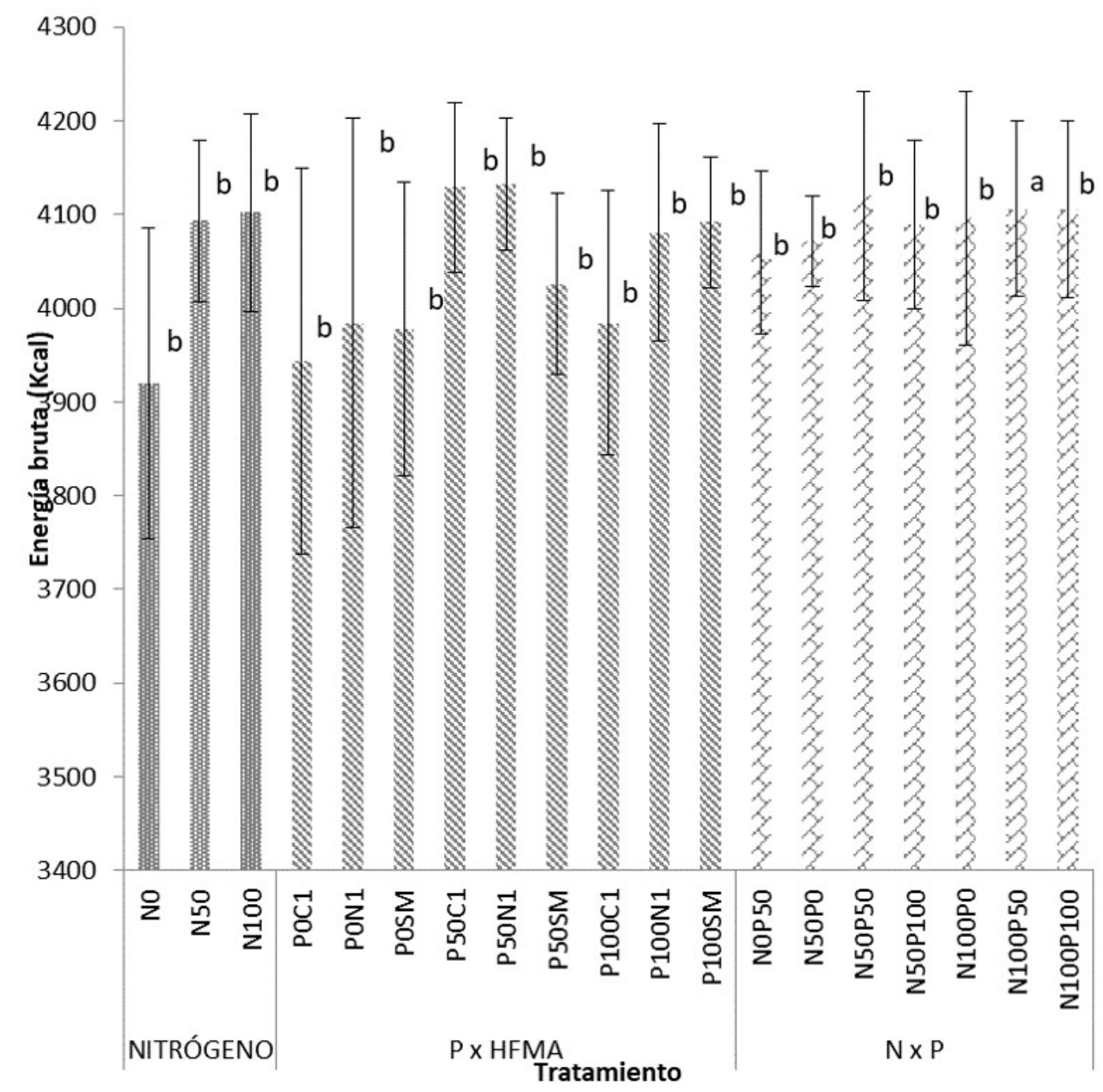

Figura 3. Efecto de la fertilización del suelo y de hongos formadores de micorrizas arbusculares (HFMA) sobre el porcentaje de energía bruta del pasto kikuyo (Cenchrus clandestinus). Letras diferentes dentro de cada grupo de tratamiento indican diferencias $(\mathrm{p}<0.05)$

gunos autores reportan que la aplicación de $\mathrm{N}$ en presencia de un nivel adecuado de $\mathrm{P}$ contribuye a una mayor actividad fotosintética y síntesis de proteína (Shahin et al., 2013). Marsalis et al. (2010) e Islam et al. (2012) encontraron que una tasa de aplicación similar a la usada en este estudio muestra una mejor concentración de PC. Asimismo, Silva et al. (2010) demostraron que la fertilización con N, P y S en el pasto kikuyo aumenta la $\mathrm{PC}$ en un $15 \%$. De igual forma, se reporta que los HFMA mejoran la calidad del pasto, principalmente el contenido de $\mathrm{PC}$ (Sabia et al., 2015), contribuyendo con la absorción de elementos como el N (Smith y Read, 2008), ya que el micelio extrarradical de los HFMA tiene la capacidad de tomar $\mathrm{NH}_{4}^{+}, \mathrm{NO}_{3}^{-}$y algunas formas de $\mathrm{N}$ orgánico 
del suelo (Tienda et al., 2014), para llevarlo a la planta y contribuir a la formación de PC.

\section{Energía}

El mayor nivel de energía se obtuvo al combinar los tratamientos de HFMA (N1) y P50, con $4145 \mathrm{kcal}$ (2039.4 kcal EM), seguido del tratamiento C1 y P50 $4129 \mathrm{kcal}$ (2051.1 kcal EM). Ambos valores de energía fueron diferentes al nivel de mayor concentración energético encontrado con los tratamiento que combinaron nitrógeno y fósforo N50 y P50 $4120 \mathrm{kcal}(2027.5 \mathrm{kcal} \mathrm{EM})(\mathrm{p}<0.05$; Figura 3). La aplicación de $\mathrm{N}$ aumentó la cantidad de energía bruta del pasto kikuyo $(p<0.05$; Figura 3), lo que indica que la fertilización con este nutriente puede afectar de manera favorable el contenido de energía del pasto. Estos valores son similares a los reportados en kikuyo por Sánchez y Soto (1999) y Dugmore (1998). Soto et al. (2005) reportaron un aumento de la concentración energética expresado como Energía Neta de Lactancia (ENL) en el pasto kikuyo al fertilizar con N. La aplicación de fertilizante con $\mathrm{N}$ se traduce en una reducción del contenido de cenizas y un aumento del EE. Además, los pastos fertilizados con $\mathrm{N}$ y $\mathrm{P}$ aumentan la tasa fotosintética $y$, por tanto, concentración carbohidratos los cuales aportan energía (Zong y Shangguan, 2014). La fertilización química mejoró los contenidos de energía y proteína (Figura 4), además de aumentar la tasa de rebrote y crecimiento, donde hay una mayor proporción de hoja que acumula material orgánico, el cual va a producir mayor energía (Juárez et al., 2009).

\section{Calcio}

La interacción N-P en los niveles N50 y P100 (Figura 5) tuvo efecto significativo en los niveles de calcio $(p<0.05)$, con una concentración promedia de $1.0 \%$, comparado con otros tratamientos que solo incluyeron la aplicación de N, P y un HFMA. El alto contenido de $\mathrm{Ca}$ se puede explicar por la posible acumulación en la pared celular al haber una mayor dosis de N, ya que aumenta su división y tamaño para favorecer el crecimiento de la planta (Marais et al., 1997). Por otro lado, la aplicación de $\mathrm{N}$ estimula la producción de ácido oxálico, el cual atrapa el Ca y disminuye su biodisponibilidad cuando el animal consume el pasto (Marais, 1990).

\section{Fósforo}

El contenido de $P$ no fue significativo al analizar los tratamientos simples $(\mathrm{N}, \mathrm{P}$, HFMA); sin embargo, los tratamientos de N100 P50 N1 y N100 P100 C1 presentaron contenidos de $\mathrm{P}$ de $0.33 \%$ y $0.36 \%$, respectivamente (Figura 6). Los resultados indicaron que una alta aplicación de $\mathrm{N}$ y $\mathrm{P}$ aumenta el contenido de P en la planta. En este sentido, Diannelis et al. (1994), muestran que dosis elevadas de $\mathrm{N}$ interactúan con el $\mathrm{P}$ para mejorar la calidad de las pasturas. Los resultados muestran además que los HFMA tuvieron un efecto positivo en la interacción múltiple de las dosis de N, P y HFMA, efecto que se puede explicar debido a la velocidad reducida con la que las raíces de la planta toman el P del suelo (Li et al., 1991), y donde los HFMA cumplen la función de aumentar la capacidad de absorber $P$ de 6 a 10 veces más que los pelos radicales (Smith et al., 1994), independientemente de la especie de HFMA. Miranda y Forsythe (2012) encontraron, por otro lado, que $R$. intraradices aumenta la cantidad de $\mathrm{P}$ en los tejidos foliares cuando este elemento se encuentra en el suelo en altas concentraciones.

\section{Contenido de proteina cruda y energía} bruta

Los niveles de tratamientos de la interacción de N, P y HFMA que mostraron un contenido de proteína cruda por encima de $18 \%$ y energía bruta sobre 4.0 Mcal EB $\mathrm{kg} \mathrm{MS}^{-1}$ (Figura 4), fueron N100-P50-N1, N100-P50-N1, N50-P0-C1, N0-P100-N1 y el nivel N50-P0-N1. Los tratamientos para estas dos variables fueron $\mathrm{N} 0-\mathrm{P} 0-\mathrm{C} 1$ y N0P0-SM (Figura 4). 


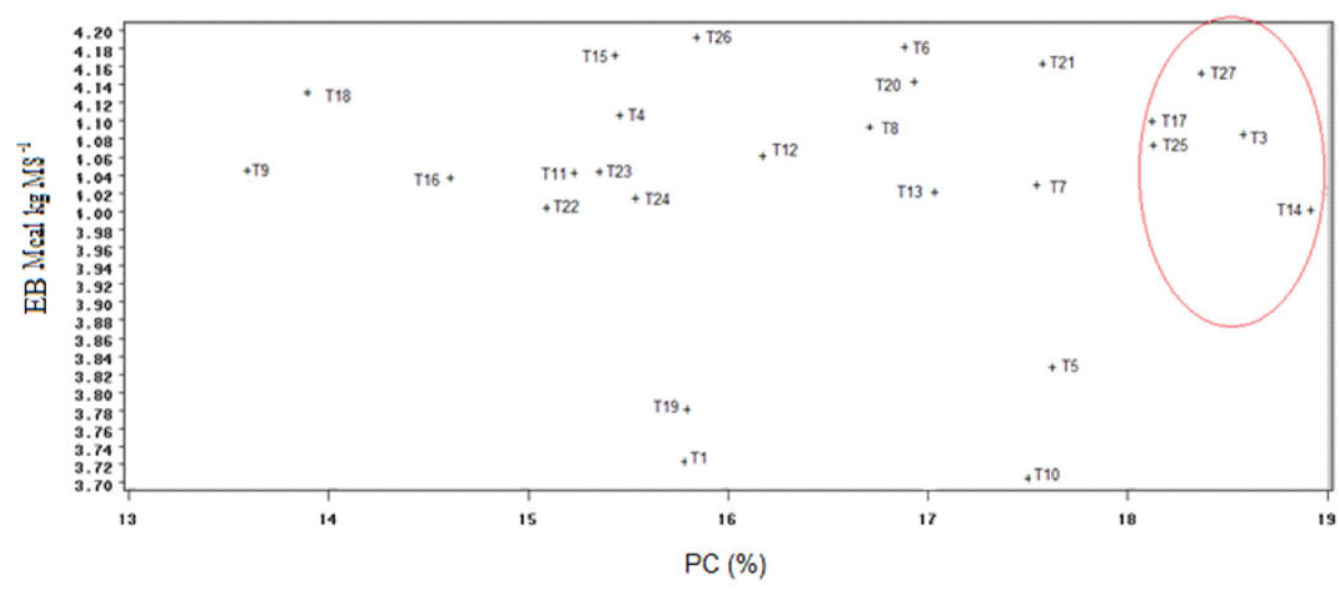

Tratamiento (M-N-P): T1: 3-1-1 T2: 3-2-3 T3: 2-3-2 T4:1-3-1 T5: 3-1-3 T6: 3-2-2 T7:2-2-1 T8:1-3-3 T9:31-2 Tl0:2-1-1 Tl1:2-2-3 Tl2: 1-3-2 Tl3: 3-3-1 Tl4: 2-1-3 Tl5: 2-2-2 Tl6: 1-2-1 T17: 3-3-3 T18:2-1-2 T19: 1-1-1 T20:1-2-3 T21: 3-3-2 T22:2-3-1 T23:1-1-3 T24:1-2-2 T 25:3-2-1 T26: 2-3-3 T27: 1-1-2

Figura 4. Niveles de la interacción de los tratamientos con de hongos formadores de micorrizas arbusculares (HFMA) (M), nitrógeno (N) y fósforo (P) sobre el contenido de proteína cruda $(\mathrm{PC}, \%)$ y energía bruta (EB, Mcal $\mathrm{kg} \mathrm{MS}^{-1}$ ) en el pasto kikuyo. Los niveles de tratamientos de la interacción de N, P y HFMA que mostraron un contenido de proteína cruda por encima de $18 \%$ y energía bruta sobre $4.0 \mathrm{Mcal} \mathrm{EB} \mathrm{kg} \mathrm{MS}^{-1}$ se encuentran señalados por el círculo rojo. Niveles para M: 1- Sin HFMA, 2- R. intraradices, 3- R. manihotis Niveles para N: 1- 0\%, 250\%, 3-100\%. Niveles para P: 1- 0\%, 2- 50\%, 3- 100\%

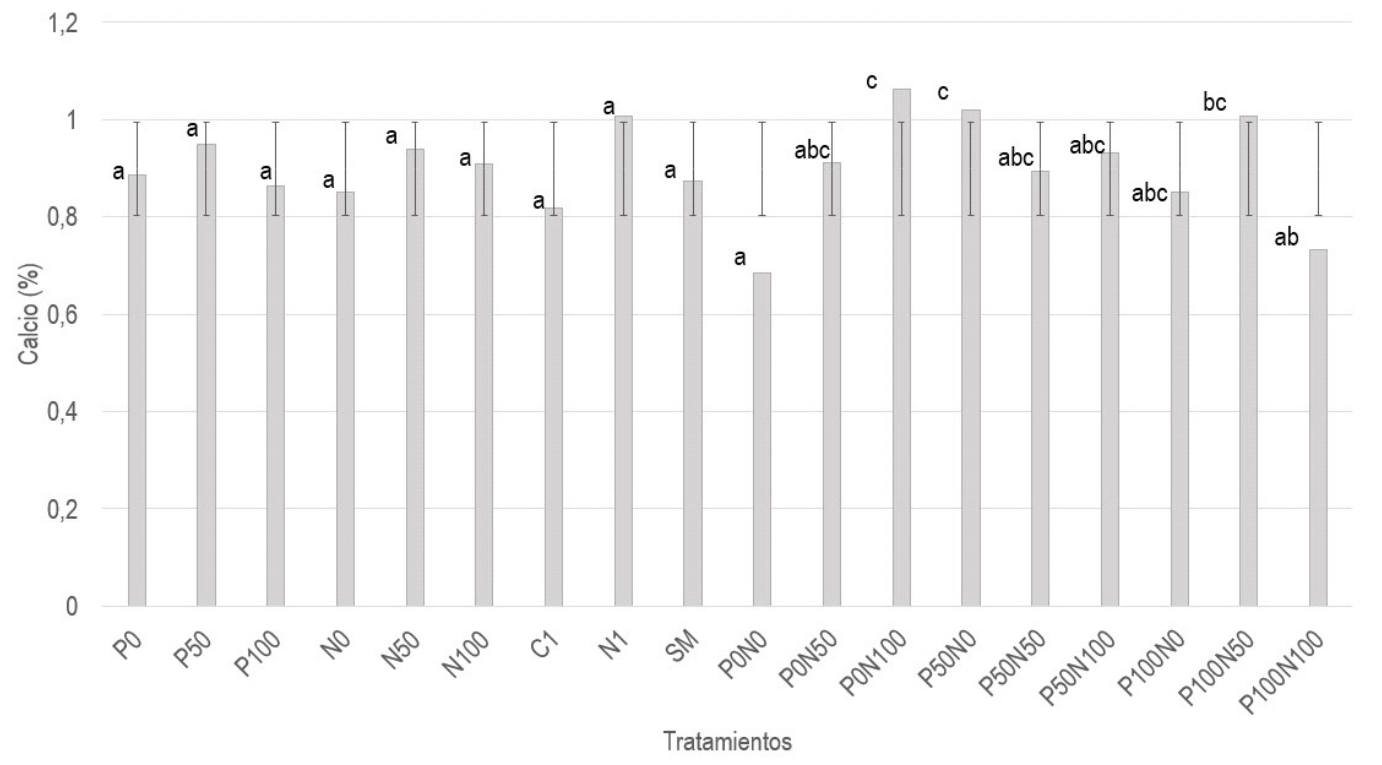

Figura 5. Efecto de la fertilización del suelo y de hongos formadores de micorrizas arbusculares (HFMA) sobre el porcentaje de calcio del pasto kikuyo (Cenchrus clandestinus). Letras diferentes dentro de cada grupo de tratamiento indican diferencias $(\mathrm{p}<0.05)$ 


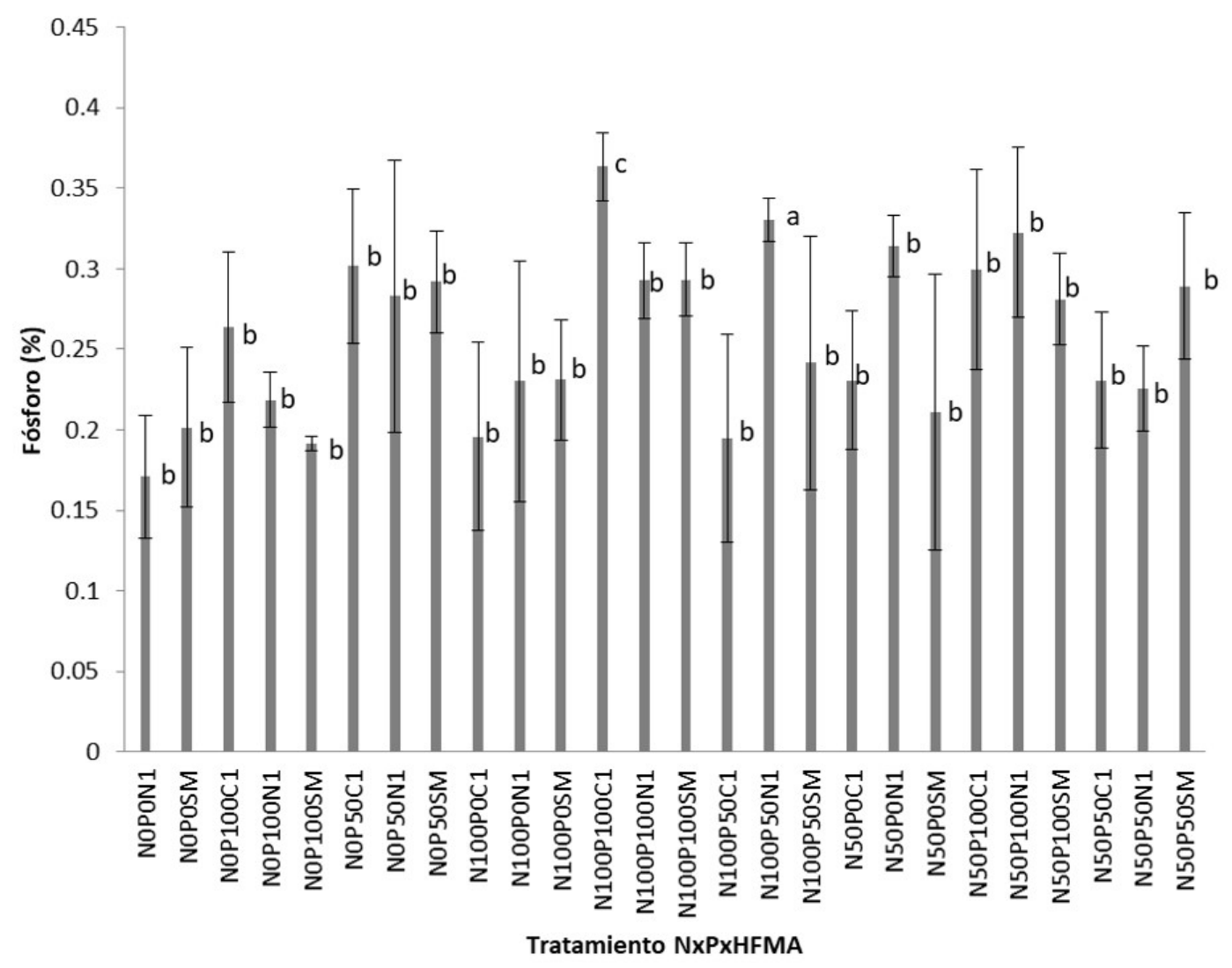

Figura 6. Efecto de la fertilización del suelo y de hongos formadores de micorrizas arbusculares (HFMA) sobre el porcentaje de fósforo del pasto kikuyo (Cenchrus clandestinus). Letras diferentes dentro de cada grupo de tratamiento indican diferencias $(\mathrm{p}<0.05)$

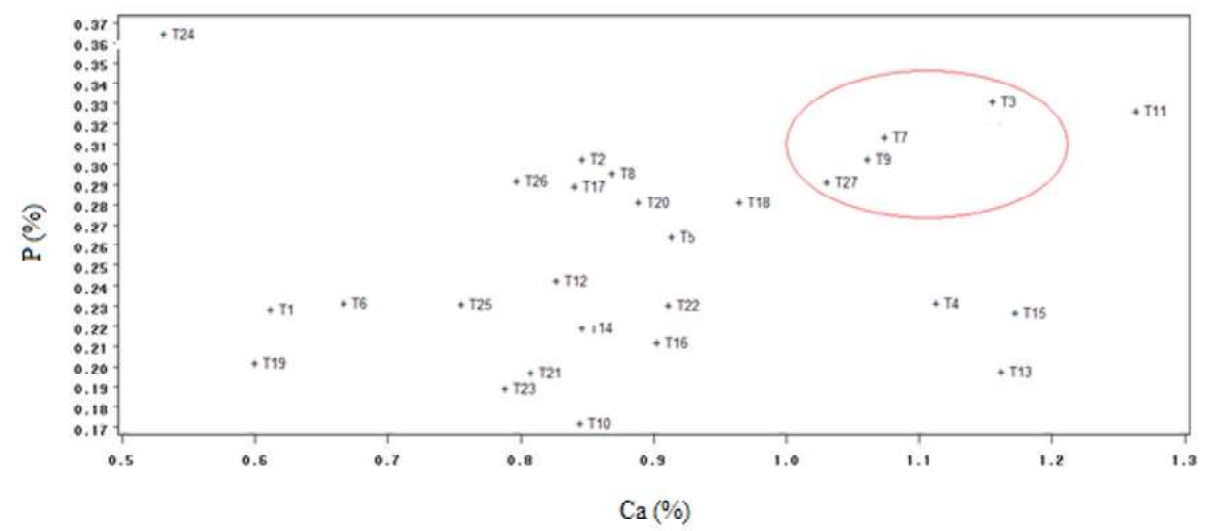

Tratamiento (M-N-P): T1: 3-1-1 T2: 3-2-3 T3: 2-3-2 T4:1-3-1 T5: 3-1-3 T6: 3-2-2 T7:2-2-1 T8:1-3-3

T9:3-1-2 T10:2-1-1 T11:2-2-3 T12: 1-3-2 T13: 3-3-1 T14: 2-1-3 T15: 2-2-2 T16: 1-2-1 T17: 3-3-3 T18:2

1-2 T19: 1-1-1 T20:1-2-3 T21: 3-3-2 T22:2-3-1 T23:1-1-3 T24:1-2-2 T 25: 3-2-1 T26: 2-3-3 T27: 1-1-2

Figura 7. Niveles de la interacción de los tratamientos con hongos formadores de micorrizas arbusculares (HFMA) (M), nitrógeno (N) y fósforo (P) sobre el contenido de $\mathrm{Ca}(\%)$ y $\mathrm{P}(\%)$ en el pasto kikuyo. Círculo rojo indica los tratamientos con mejores medidas en ambas variables. Niveles para M: 1- Sin HFMA, 2- $R$. intraradices, 3- $R$. manihotis Niveles para N: 1- 0\%, 2$50 \%, 3-100 \%$ Niveles para P: 1- 0\%, 2- 50\%, $3-100 \%$ 


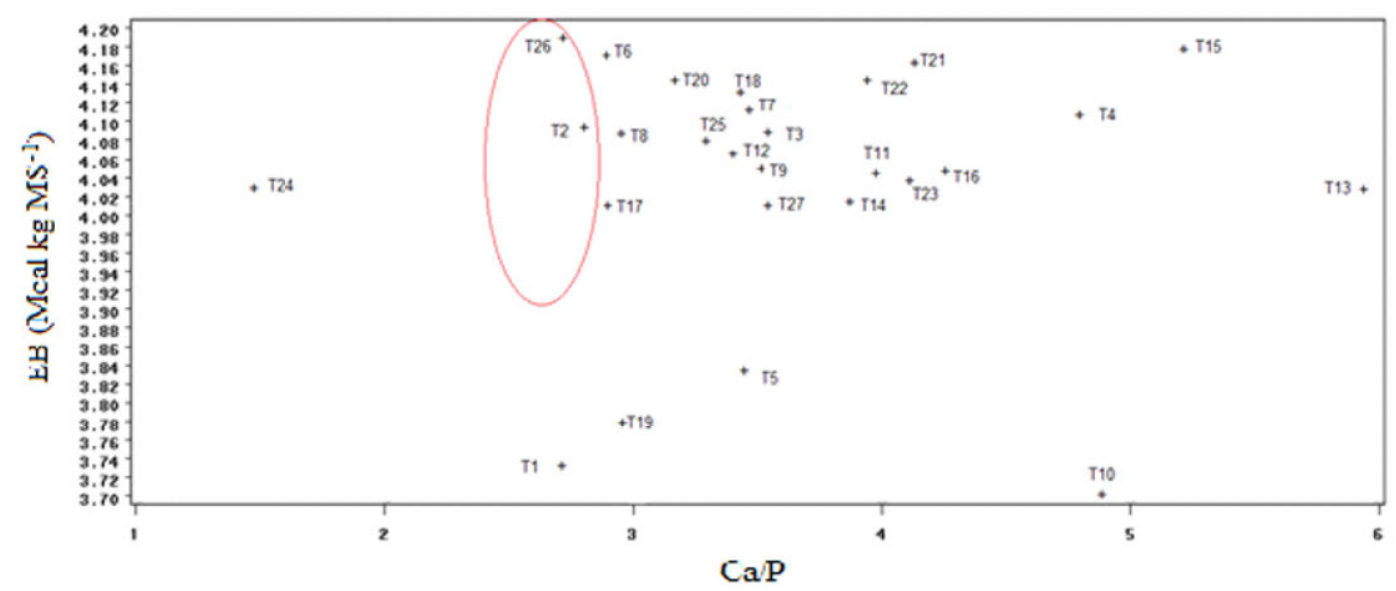

Tratumiento $(M-N-P):$ T1: 3-1-1 T2: 3-2-3 T3:2-3-2 T4:1-3-1 T5: 3-1-3 T6: 3-2-2 T7:2-2-1 T8:1-3-3 T9:3-1-2 T10:2-1-1 T11:2-2-3 T12: 1-3-2 T13: 3-3-1 T14: 2-1-3 T15: 2-2-2 T16: 1 2-1 T17: 3-3-3 T18:2-1-2 T19: 1-1-1 T20:1-2-3 T21:3-3-2 T22:2-3-1 T23:1-1-3 T24:1-2-2 T 25: 3-2-1 T26: 2-3-3 T27: 1-1-2

Figura 8. Niveles de la interacción de los tratamientos con hongos formadores de micorrizas arbusculares (HFMA) (M), nitrógeno (N) y fósforo (P) en las variables dependientes energía bruta (EB) (Mcal kg MS-1) y la relación Ca y P en el pasto kikuyo. Círculo rojo indica los tratamientos con mejores medidas en ambas variables. Niveles para M: 1- Sin HFMA, 2- $R$. intraradices, 3- $R$. manihotis Niveles para N: 1- 0\%, 2- 50\%, $3-100 \%$ Niveles para P: 1- 0\%, 2- $50 \%, 3-100 \%$

Contenido de calcio y fósforo

Los niveles de los tratamientos de la interacción de N-P y HFMA con la mayor concentración de Ca y P fueron N50-P100N1 y N100-P50-N1 y los de menor concentración fueron N0-P0-C1 y N0-P0-SM (Figura 7).

Concentración de energía bruta y minerales

La relación entre los minerales y la concentración energética del pasto kikuyo mostraron una relación calcio/fósforo entre $3 / 4$ y una concentración de energía superior a 4.0 Mcal EB kg MS ${ }^{-1}$, excepto en los niveles de los tratamientos N0-P0-C1 y N0-P0-SM (Figura 8).

\section{Colonización de Raíces}

En la colonización consideraron los niveles de fertilización de 0,50 y $100 \%$ para el $\mathrm{N}$ y el $\mathrm{P}$, además de los grupos de HFMA nativos al pasto kikuyo ( $R$. intraradices y $R$. fasciculatus) y una especie diferente a las halladas en este pasto ( $R$. manihotis). Los resultados muestran que solo los tratamientos con HFMA fueron significativos $(\mathrm{p}<0.05)$ para la colonización, dado que los niveles de fertilización no tuvieron efecto $(p>0.05)$ en el porcentaje de colonización en las raíces del pasto kikuyo.

El porcentaje de colonización no fue afectado por el tipo de mineral y el nivel de fertilizante aplicado. Qin et al. (2015) encontraron un efecto positivo en la población de 


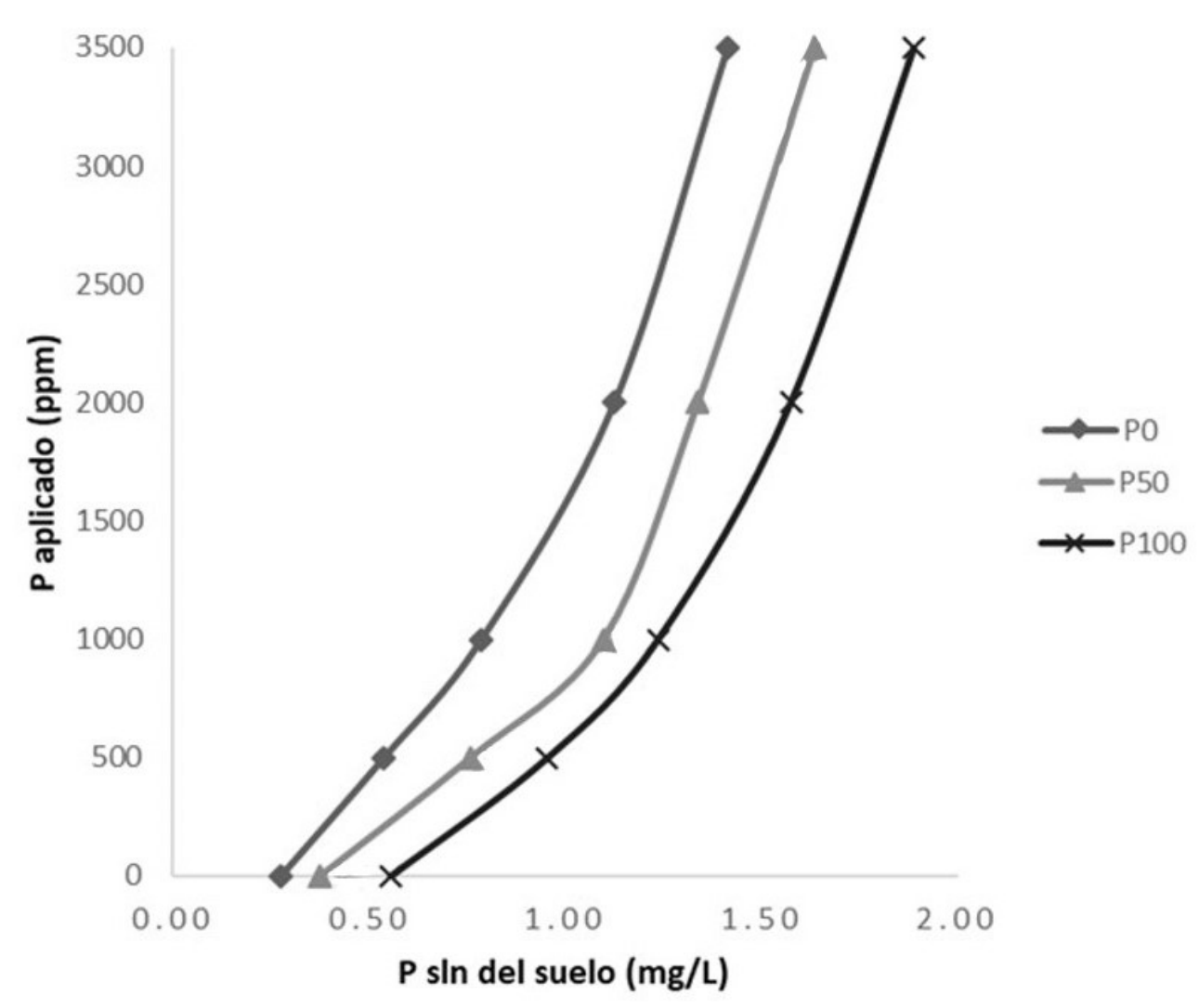

Figura 9. Isoterma de adsorción de $\mathrm{P}$ para cuatro niveles de $\mathrm{P}(0,50$ y $100 \%)$. La curva indica que un aumento en la aplicación de $\mathrm{P}$ como fertilizante químico aumenta la cantidad de este elemento en la solución del suelo.

microorganismos de la rizosfera, pero no en la colonización de la raíz por parte de los HFMA cuando hay aplicación de fertilizantes químicos. No obstante, Lin et al. (2012) demostró que altas aplicaciones de $\mathrm{Ny} \mathrm{P}$ afectan la población de microorganismos como los HFMA y el porcentaje de colonización en las raíces de las plantas, efecto que se debe probablemente a la preferencia de los HFMA por un $\mathrm{pH}$ neutro o cercano a la alcalinidad (Qin et al., 2015). Sin embargo, algunas especies de HFMA parecen responder de manera diferente a la aplicación de fertilizantes, como por ejemplo $R$. intraradices (Bhadalung et al., 2005), especie que se empleó en este estudio y que fue aislada de los suelos establecidos en pasto kikuyo en algunos municipios de clima frío en Antioquia, la cual mostró los mejores resultados.

\section{Isotermas de Adsorción de Fósforo}

En la variable $\mathrm{P}$ se agruparon los niveles (P0\%, P50\% y P $100 \%$ ) y para los HFMA los niveles ( $\mathrm{SM}, \mathrm{R}$. intraradices, $\mathrm{R}$. fasciculatus y R. manihotis). Cuando las cantidades de $\mathrm{P}$ aplicado al suelo fueron de 0,500 y $1000 \mathrm{mg} \mathrm{kg}^{-1}$ hubo un efecto significativo $(p<0.05)$ de los HFMA en la cantidad de $\mathrm{P}$ en la solución del suelo ( $\mathrm{mg}^{1^{-1}}$ ); más no así para las aplicaciones de 2000 y $3500 \mathrm{mg}$ $\mathrm{kg}^{-1}$ de P. La interacción entre los niveles de HFMA y el P no tuvieron un efecto en cada una de las concentraciones; sin embargo, la aplicación de $\mathrm{P}$ en niveles de 0,50 y $100 \%$ para la dosis de $200 \mathrm{~kg}$ de $\mathrm{P} \mathrm{ha}^{-1}$ año ${ }^{-1}$ tuvo efecto significativo $(p<0.05)$ en la concentración de $\mathrm{P}$ en la solución del suelo $\left(\mathrm{mg}^{\mathrm{l}^{-1}}\right)$ 
en las cantidades de $\mathrm{P}$ aplicado $(0,500,1000$, 2000 y 3500 ppm) (Figura 9).

El suelo debe contener la suficiente concentración de $\mathrm{P}$ para proveer el gradiente necesario para su movimiento hacia las raíces (Fox y Kamprath, 1970; Correa y Jaramillo, 1985). El presente estudio demostró que la asociación micorrizal permite un aumento en la toma del $\mathrm{P}$ disponible en el suelo para el pasto kikuyo. Resultados similares han sido reportados en otras plantas (Barea et al., 2008), indicando que este tipo de pastos son dependientes de la asociación con HFMA (Habte y Manjunath, 1991). Los HFMA son capaces de explorar un mayor volumen de suelo y pueden tomar más $\mathrm{P}$, incluso a concentraciones bajas y donde la raíz de la planta no es capaz de tomarlo (Grace et al., 2009).

Los resultados indican que, al aumentar la cantidad de $\mathrm{P}$ aplicado como fertilizante químico, el $\mathrm{P}$ en solución también sufre el mismo comportamiento (Figura 9). Según Kirkby y Johnston (2008), altas aplicaciones de P son necesarias para llegar a tener niveles de suficiencia de este elemento para la absorción de la planta en suelos que se caracterizan por tener alta capacidad de fijación de fosfatos. Gran parte de los suelos bajo los cuales se encuentra establecido el pasto kikuyo en el trópico alto colombiano son suelos derivados de cenizas volcánicas, los cuales se caracterizan por presentar alta capacidad de fijación de fósforo (Correa y Jaramillo, 1985). La presencia de HFMA en estos suelos mejora la adsorción de este elemento facilitando la nutrición vegetal con $\mathrm{P}$ y mejorando la calidad nutricional y productividad de este pasto.

\section{Conclusiones}

- Las aplicaciones de fertilizantes químicos influyen en la calidad nutricional del forraje. La dosis de nitrógeno de $400 \mathrm{~kg}$ $\mathrm{N} \mathrm{ha}^{-1}$ año ${ }^{-1}$ combinada con niveles de $\mathrm{P}$ de $100 \mathrm{~kg} \mathrm{P} \mathrm{ha-1} \mathrm{año}{ }^{-1}$ tuvieron efecto positivo en la concentración de proteína y energía del pasto kikuyo.

- El empleo de estas dosis racionales de $\mathrm{N}$ y $\mathrm{P}$ junto con los HFMA en condiciones controladas en los planes de fertilización de pasto kikuyo permite mejorar algunas de las variables bromatológicas tales como la energía, proteína, la materia seca y fósforo, además disminuye el efecto negativo de las altas aplicaciones de fertilizantes nitrogenados y fosforados al medio ambiente.

- Las altas dosis de nitrógeno de $400 \mathrm{~kg} \mathrm{~N}$ $\mathrm{ha}^{-1}$ año $^{-1}$ no afectan el desempeño del HFMA nativo Rhizophagus intraradices encontrado en las praderas del pasto kikuyo.

- $\quad$ El uso de HFMA en suelos de trópico alto, que en su mayoría son suelos fijadores de fosfatos, mejoran la absorción de fósforo facilitando la nutrición vegetal con este elemento, la calidad nutricional y la producción del pasto kikuyo.

\section{Agradecimientos}

Los autores expresan sus agradecimientos a la sostenibilidad de grupo GRICA 2018 -2020 de la Facultad y al químico Silvio Ayala L por sus aportes.

\section{Literatura Citada}

1. Agudelo GG 2001. Fundamentos de nutrición animal aplicada. Colombia: $\mathrm{Ed}$ Universidad de Antioquia. $348 \mathrm{p}$.

2. Alvarado CM, Díaz FA, Hernández MR. 2014. Tecnología para producir tomate en casa malla para el norte de Tamaulipas. México: Secretaría de Agricultura. Ganadería, Desarrollo Rural, Pesca y Alimentación. $31 \mathrm{p}$.

3. A.O.A.C. 1990. Official methods of analysis. Association of official agricultural chemists. $15^{\text {th }}$ ed. Helrich K (ed). Association of Official Analytical Chemists. Arlington, Virginia, USA. 1141 p. 
4. A.O.A.C. 1995. Official Methods of Analysis of AOAC International. $16^{\text {th }} \mathrm{ed}$. Cunnif P (ed). Association of Official Analytical Chemists. Arlington, Virginia, USA.

5. Adesemoye AO, Kloepper J. 2009. Plant-microbes interactions in enhanced fertilizer-use efficiency. Appl Microbiol Biot 85: 1-12. doi: 10.1007/s00253-0092196-0

6. Apráez JE, Moncayo AO. 2003. Caracterización agronómica y bromatológica de una pradera de kikuyo (Cenchrus clandestinum (Hoechst ex Chiov. Morrone) sometida a rehabilitación mediante labranza y fertilización orgánica y/o mineral. Colombia Lead 10: 25-35.

7. Aseri GK, Jain N, Panwar J, Rao AV, Meghwal PR. 2008. Biofertilizers improve plant growth, fruit yield, nutrition, metabolism and rhizosphere enzyme activities of pomegranate (Punica granatum $\mathrm{L}$ ) in Indian Thar Desert. Sci Hortic-Amsterdam 117: 130-135. doi: 10.1016/j.scienta.2008.03.014

8. Ayala $S A$. 2007. Manual para el laboratorio de nutrición animal. Antioquia, Colombia: Univ. de Antioquia. 41 p.

9. Barea JM, Ferrol N, Azcón-Aguilar C, Azcón R. 2008. Mycorrhizal symbioses. In: White PJ, Hammond JP (eds). The ecophysiology of plantphosphorus interactions. Plant Ecophysiol 7: 143-163.

10. Bhadalung NN, Suwanarit A, Dell B, Nopamornbodi $O$, Thamchaipenet A, Rungchuang J. 2005. Effects of longterm NP-fertilization on abundance and diversity of arbuscular mycorrhizal fungi under a maize cropping system. Plant Soil 270: 371-382.

11. Chopra BK, Bhat S, Mikheenko IP, Xu $Z$, Yang Y, Luo X, Chen $H$, et al. 2007. The characteristics of rhizosphere microbes associated with plants in arsenic- contaminated soils from cattle dip sites. Sci Total Environ 378: 331-342. doi: 10.1016/j.scitotenv.2007.02.036
12. Correa HJ, Pabón ML, Sanchéz MY, Carulla JE. 2011. Efecto del nivel de suplementación sobre el uso del nitrógeno, el volumen y la calidad de la leche en vacas Holstein de primero y segundo tercio de lactancia en el trópico alto de Antioquia. Livestock Res Rural Dev. 23(77). [Internet]. Disponible en: http:// www.1rrd.org/lrrd23/4/corr23077.html

13. Correa ID, Jaramillo CM. 1985. Mecanismos de adsorción de fósforo en andisoles del oriente Antioqueño. Medellín, Colombia: Univ. Nacional de Colombia. $87 \mathrm{p}$.

14. Diannelis C, Urbano Y, Arrojas I, Dávila C. 1994. Efecto de la fertilización en la asociación kikuyo-alfalfa. (Pennisetum clandestinum-Medicago sativa). 1. Producción de materia seca, altura y relación hoja - tallo. Zootec Trop 12: 281-306.

15. Dugmore TJ. 1998. Energy and mineral content of kikuyu. In: Bartholomew PE (ed). Proc Kikuyu Technology Day. Agriculture and Rural Department. South Africa.

16. Echeverri J, Restrepo LF, Parra J. 2010. Evaluación comparativa de los parámetros productivos y agronómicos del pasto kikuyo (Cenchrus clandestinus bajo dos metodologías de fertilización. Rev Lasallista Investig 7: 94-100.

17. Estrada J. 2001. Pastos y forrajes para el trópico colombiano. Manizales, Colombia: Univ. de Caldas. $511 \mathrm{p}$.

18. Fox R, Kamprath E. 1970. Phosphate sorption isotherms for evaluating the phosphate requirements of soils. Soil Sci Soc Am J 34: 902-907. doi: 10.2136/ sssaj1970.03615995003400060025x

19. Giovannetti M, Mosse B. 1980. An evaluation of technique for measuring vesicular - arbuscular mycorrhizal infection in roots. New Phytol 84: 489-500.

20. Giovannetti M, Avio L, Fortuna $P$, Pellegrino E, Sbrana C, Strani P. 2006. At the root of the wood wide web. Self recognition and nonself incompatibility in mycorrhizal networks. Plant Signal Behav 1: 1-5. doi: 10.4161/psb.1.1.2277 
21. Grace EJ, Cotsaftis O, Tester M, Smith FA, Smith SE. 2009. Arbuscular mycorrhizal inhibition of growth in barley cannot be attributed to extent of colonization, fungal phosphorus uptake or effects on expression of plant phosphate genes. New New Phytol 181: 938- 949. doi: 10.1111/j.1469-8137.2008.02720.x

22. Gyaneshwar P, Kumar GN, Parekh LJ, Poole PS. 2002. Role of soil microorganisms in improving P nutrition of plants. Plant Soil 245: 83-93. doi: 10.1023/A:1020663916259

23. Habte M, Manhunath A. 1991. Categories of vesicular - arbucular mycorrizal dependency of host especies. Mycorrhiza 1: 3-12.

24. Habte M, Osorio NW. 2001. Arbuscular mycorrhizas: producing and applying arbuscular mycorrhizal inoculum. Honolulu: University of Hawaii. 47 p.

25. Islam M, García S, Horadagoda A. 2012. Effects of irrigation and rates and timing of nitrogen fertilizer on dry matter yield, proportions of plant fractions of maize and nutritive value and in vitro gas production characteristics of whole crop maize silage. Anim Feed Sci Tech 172: 125-135. foi: $10.1016 / j$.anifeedsci.2011.11.013

26. Juárez AS, Cerrillo SA, Gutiérrez OE, Romero TE, Colín NJ, Bernal BH. 2009. Assessment of the nutritional value of tropical grasses obtained from conventional analyses and in vitro gas production. Tec Pecu Mex 47: 55-67

27. Kirkby EA, Johnston AE. 2008. Soil and fertilizer phosphorus in relation to crop nutrition. In: White PJ, Hammond JP (eds). The ecophysiology of plantphosphorus interactions. New York: Springer. p 177-223.

28. Li XL, Marschner H, George E. 1991. Acquisition of phosphorus and copper by VA-mycorrhizal hyphae and root-toshoot transport in white clover. Plant Soil 136: 49-57. doi: 10.1007/BF02465219
29. Lin X, Feng Y, Zhang H, Chen R, Wang J, Zhang J, Chu H. 2012. Longterm balanced fertilization decreases arbuscular mycorrhizal fungal diversity in an arable soil in North China revealed by 454 pyrosequencing. Environ Sci Technol 46: 5764-5771. doi: 10.1021/ es3001695

30. Marais JP, Barnabas AD, Figenschou DL. 1997. Effect of calcium nutrition on the formation of calcium oxalate in kikuyu grass. In: XVIII International Grassland Congress. Canada.

31. Marais JP. 1990. Effect of nitrogen on the oxalate and calcium content of kikuyu grass (Pennisetum clandestinum Hochst). Afr J Range Forage Sci 7: 106110. doi: 10.1080/02566702.1990.9648215

32. Marsalis M, Angadi S, Contreras GF. 2010. Dry matter yield and nutritive value of corn, forage sorghum, and BMR forage sorghum at different plant populations and nitrogen rates. Field Crop Res 116: 52-57. doi: 10.1016/ j.fcr.2009.11.009

33. Miranda MH, Forsythe JA. 2012. Using arbuscular mycorrhizal fungi to improve the nutrient quality of crops; nutritional benefits in addition to phosphorus. Sci Hortic-Amsterdam 148: 206-214. doi: 10.1016/j.scienta.2012.09.018

34. Ortiz A, Medina M, Echeverri J. 2017. Identificación de algunas cepas de hongos micorrícicos asociados al kikuyo (Cenchrus clandestinus (Hochst ex Chiov) Morrone) y su efecto en algunas variables agronómicas. Livestock Res Rural Dev 29(5). [Internet]. Disponible en: https://www.lrrd.cipav.org.co/lrrd29/ 5/orti29088.html

35. Phillips JM, Hayman DS. 1970. Improved procedures for clearing and staining parasitic and vesiculararbuscular mycorrhizal fungi for rapid assessment of infection. T Brit Mycol Soc 55: 158-161. doi: 10.1016/S00071536(70)80110-3 
36. Qin H, Lu K, Strong PJ, Xu Q, Wu Q, $X u Z, X u J$, Wang H. 2015. Long-term fertilizer application effects on the soil, root arbuscular mycorrhizal fungi and community composition in rotation agriculture. Appl Soil Ecol 89: 35-43. doi: 10.1016/j.apsoil.2015.01.008

37. Sabia ES, Claps F, Napolitano G, Annicchiarico A, Bruno R, Francaviglia L, Aleandri R. 2015. In vivo digestibility of two different forage species inoculated with arbuscular mycorrhiza in Mediterranean red goats. Small Ruminant Res 123: 83-87. doi: 10.1016/j.smallrumres.2014.10.008

38. Sánchez GJ, Soto MH. 1999. Estimación de la calidad nutricional de los forrajes del Cantón de San Carlos III. Energía para la producción de leche. Nutr Anim Trop 5. 31- 49.

39. Shahin MG, Abdrabou RTh, Abdelmoemn WR, Hamada MM. 2013. Response of growth and forage yield of pearl millet (Pennisetum glaucum) to nitrogen fertilization rates and cutting height. Ann Agric Sci 58: 153-162. doi: 10.1016/j.aoas.2013.07.009

40. Sierra EJ, Castro RD, Osorio VW. 2012. Mycorrhizal dependence of barcino (Clusiaceae: Calophyllum brasilience cambers). Actual Biol 34: 199-206.

41. Sieverding E. 1984. Manual de métodos para la investigación de micorriza vesiculo-arbuscular en el laboratorio. Cali, Colombia: Centro Internacional de Agricultura Tropical CIAT. 96 p.

42. Silva A, Menjivar JC, Alava CA, Gómez HF. 2010. Efecto de la fertilización con nitrógeno, fósforo y azufre sobre la recuperación de una pradera degradada de kikuyo (Pennisetum clandestinum Hoechst) en Nariño, Colombia. En: XII Congreso Ecuatoriano de la Ciencia del suelo. Ecuador.

43. Smith SD, Read DJ. 2008. Mycorrhizal symbiosis. $3^{\text {rd }}$ ed. New York; Academic Press. 800.
44. Smith KG, Smith KA, O'Bannon DP, Olian JD, Sims HP, Scully J. 1994. Top management team demography and process: the role of social integration and communication. Admin Sci Quart 39: 412-438. doi: 10.2307/2393297

45. Soto C, Valencia A, Galvis RD y Correa HJ. 2005. Efecto de la edad de corte y del nivel de fertilización nitrogenada sobre el valor energético y proteico del pasto kikuyo (Pennisetum clandestinum). Rev Colomb Cienc Pec 18: 17-26.

46. Steinshamn H, Thuen E, Bleken MA, Brenoe UT, Ekerholt G, Yri C. 2004. Utilization of nitrogen (N) and phosphorus $(\mathrm{P})$ in an organic dairy farming system in Norway. Agr Ecosyst Environ 104: 509-522. doi: 10.1016/ j.agee.2004.01.022

47. Swanepoel PA, Bothaa PR, Preez CC, Snymanc HA. 2013. Physical quality of a podzolic soil following 19 years of irrigated minimum-till kikuyu-ryegrass pasture. Soil Till Res 133: 10-15. doi: 10.1016/j.still.2013.05.008

48. Teixeira EI, George M, Herreman T, Brown H, Fletche A, Chakwizira, Ruite J, et al. 2014. The impact of water and nitrogen limitation on maize biomass and resource - use efficiencies for radiation water and nitrogen. Field Crop Res 168: 109-118. doi: 10.1016/ j.fcr.2014.08.002

49. Tienda PJ, Correa A, Azcón AC, Ferrol N. 2014. Transcriptional regulation of host $\mathrm{NH}_{4}+$ transporters and GS/GOGAT pathway in arbuscular mycorrhizal rice roots. Plant Physiol Bioch 75: 1-8. doi: 10.1016/j.plaphy.2013.11.029

50. Zong Yu Z, Shangguan ZP. 2014. Nitrogen deficiency limited the improvement of photosynthesis in maize by elevated $\mathrm{CO}_{2}$ under drought. J Integr Agr 13: 73-81. doi: 10.1016/S20953119(13)60349-4 